\title{
Immobilised Co(II) Homodinuclear Coordinative Compound with Terephthalate and o-phenanthroline as Ligands: Synthesis, Crystal Structure and Applications
}

\author{
Catalin Blegescu, ${ }^{1}$ Dumitru Ganju, ${ }^{1}$ Sergiu Shova, ${ }^{2}$ Doina Humelnicu ${ }^{1, *}$
}

\footnotetext{
1 "Al.I. Cuza" University of lasi, Faculty of Chemistry, Carol I, nr. 11 Bld., lasi, 700506, Romania

2 "Petru Poni" Institute of Macromolecular Chemistry, Aleea Gr. Ghica Voda 41 A, lasi, 700487, Romania

* Corresponding author's e-mail address: doinah@uaic.ro
}

RECEIVED: January 10, 2017 * REVISED: March 31, 2017 * ACCEPTED: April 8, 2017

Abstract: Homodinuclear coordinative compound of $\mathrm{Co}(\mathrm{II})$ with terephthalate bridge and o-phenanthroline has been synthesized and
characterized by elemental analysis, FT-IR spectroscopy, thermal analysis. The crystal structure was determined by single crystal X-ray
diffraction technique. The coordinative compound was immobilized into functionalized silica with thiol groups and tested for its catalytic activity
towards styrene oxidation in the presence of $\mathrm{H}_{2} \mathrm{O}_{2}$. A conversion of $89.75 \%$ and selectivity of $85.4 \%$ for benzaldehyde formation was obtained.

Keywords: terephthalate bridge, catalytic activity, styrene oxide, functionalised silica, o-phenanthroline.

\section{INTRODUCTION}

$\mathbf{T}$ HE chemistry of polycarboxylate-type compounds represents a great interest due to the structural diversity of the many coordination ways forming dinuclear coordinative compounds that can be used in different research fields. ${ }^{[1,2]}$

The possibility of using these classes of compounds in various fields, with practical applications such as molecular magnets, host materials like zeolites, gas storage, catalysts, materials for nonlinear optics, luminescent materials has led to the synthesis of a wide range of coordinative compounds of transition metal with different ligands. ${ }^{[3]}$

A suitable example of such ligand in order to obtain the compounds from this class is the terephthalate anion, $\mathrm{C}_{8} \mathrm{H}_{4} \mathrm{O}_{4}{ }^{2-}$.

This ligand can bind two identical or different metal cations in many ways to form two- or three-dimensional coordinative compounds.

Due to the theoretical possibilities of coordinating the terephthalate anion can work as a bidentate $(\mathrm{I}, \mathrm{V})$, tridentate (III) or tetradentate (II, IV) ligand (Figure 1). ${ }^{[4]}$

It is well known that the homogenous transition metal coordinative compounds have appreciable catalytic activity and selectivity towards oxidation of different olefins. ${ }^{[5-9]}$ The majority of such catalysts have some disadvantages such as: difficulties in the separation of the product, recovery and recycling of the catalysts, deactivation, that make them difficult to apply on a large scale. ${ }^{[10]}$ From these reasons the heterogeneity of an active metal coordinative compound on solid supports is receiving great interest for oxidation of various olefins. Such a heterogeneity method consists in anchoring to a chemically inert solid supports, ${ }^{[11,12]}$ mesoporous silica SBA-15 (Santa Barbara Amorphous type material), ${ }^{[13]}$ MCM-41 (Mobil Crystalline Materials), ${ }^{[14]}$ ion exchange into zeolite $Y_{,}{ }^{[15]}$ zeolite $X,{ }^{[16]}$ clays. ${ }^{[17]}$

Nowadays, to combine the advantages of both homogeneous and heterogeneous catalytic systems, heterogeneity of homogeneous catalysts on solid supports has been initiated. ${ }^{[18-20]}$ 
<smiles>[M]OC(=O)c1ccc(C(=O)O[M])cc1</smiles>

I.<smiles>[M]OC(Oc1ccoc1)=C1CO1</smiles>

II.<smiles>[M]OC(=O)c1ccc(C(=O)O[M])cc1</smiles>

III.<smiles>[M]OC(=O)c1ccc(C(=O)O[M])cc1</smiles>

IV.<smiles>[M]OC(=O)c1ccc(C(=O)O)cc1</smiles>

V.

Figure 1. Coordination possibilities of terephthalate anion.

Silica supports are a special category of materials due to the complexity and versatility of their structure. ${ }^{[21]}$

The functionalisation of the support material can be performed by use of a grafting agent chemically bonded on the silica matrix surface, ${ }^{[22]}$ or by chemical generate of functional groups on the surface by using a specific chemical reaction. ${ }^{[23]}$

The immobilization process has the effect of increasing the heterogeneity of the active centre and its surface area in order to obtain an increased catalytic potential.

Mainly, the immobilization of a coordination compound on the inorganic support can be achieved in two ways: (i) by breaking a chemical bond established between one of the metal centers in coordination compounds' structure and forming a new, stronger one between it and a functional group of the inorganic support; (ii) immobilization by ion exchange. The advantage of this kind of immobilization consists in the possibility to control the particle size of the active compound according to their pores size.

Such of materials have been obtained over time, most of them having as central component a transition metal coordinative compound with high molecular organic ligands such as Schiff bases. ${ }^{\text {[24-27] }}$

The present work presents the synthesis of coordinative compound of cobalt (II) with o-phenanthroline and a terephthalate bridge and the immobilization on functionalised silica as support. The obtained compound was characterized by elemental analyzes, Fourier transform infrared spectra (FTIR), and single crystal X-ray diffraction. The catalytic activity of the compound has been investigated and compared with the results from the literature.

\section{EXPERIMENTAL}

\section{Materials and Methods}

All regents were purchased from Fluka and used without further purification. Elemental analyzes were carried out using a Perkin-Elmer 2400 II elemental analyzer. Infrared spectra were recorded with a Bruker Tensor 27 (ATR) device, and thermal analysis were performed using a Paulik Erdey type derivatograph (MOM-BUDAPEST) with a heating rate of $10{ }^{\circ} \mathrm{C} / \mathrm{min}$ between $25-750{ }^{\circ} \mathrm{C}$, in nitrogen. The specific surface of the silica matrix and its porosity were determined from the adsorption isotherms of the material at the $-196^{\circ} \mathrm{C}$ using a Quantachrome Autosorb Nova 2200e apparatus. The specific surface was calculated using the Brunauer-Emmett-Teller method ${ }^{[28]}$ while pore size distribution by Barett-Joyner-Halenda model. ${ }^{[29]}$

Crystallographic measurements were carried out with an Oxford-Diffraction XCALIBUR E CCD diffractometer equipped with graphite-monochromated Mo-K $\alpha$ radiation. The crystals were placed $40 \mathrm{~mm}$ from the CCD detector and 
355 frames were measured each for $60 \mathrm{~s}$ over $1^{\circ}$ scan width. The unit cell determination and data integration were carried out using the CrysAlis package of Oxford Diffraction. ${ }^{[30]}$ All the structures were solved by direct methods using Olex2 ${ }^{[31]}$ software with the SHELXS structure solution program and refined by full-matrix least-squares on $F_{0}{ }^{2}$ with SHELXL-97. ${ }^{[32]}$ Atomic displacements for nonhydrogen atoms were refined using an anisotropic model. The hydrogen atoms linked to carbon were placed in fixed, idealized positions and refined as rigidly bonded to the corresponding atom. Hydrogen atoms for water molecules have been placed by Fourier Difference accounting for the hybridation of the supporting atoms and the hydrogen bonds parameters. The molecular plots were obtained using the Olex2 program. ${ }^{[31]}$

The products of catalytic oxidation of the styrene were determined by gas chromatography coupled with mass spectrometry (GC-MS). For this purpose it was used a chromatograph Varian 2000 GC-MAS with $20 \mathrm{~mm} \times 0.32$ $\mathrm{mm} \times 0.25 \mu \mathrm{m}$ thickness films.

\section{Synthesis of Coordinative Compound $\left[\mathrm{CO}_{2}(\mathrm{TPh})(0 \text {-phen })_{4}\left(\mathrm{H}_{2} \mathrm{O}\right)_{2}\right](\mathrm{TPh})$}

Firstly, disodium terephthalate was prepared by the reaction between an aqueous solution of terephthalic acid and the appropriate amount of sodium bicarbonate under continuous stirring until the effervescence disappeared.

Subsequently, the metal cations were precipitated with a solution of sodium terephthalate in a mole ratio $\mathrm{Co}\left(\mathrm{NO}_{3}\right)_{2}: \mathrm{Na}_{2} \mathrm{C}_{8} \mathrm{H}_{4} \mathrm{O}_{4}=2: 1$. The reaction was carried out in dilute aqueous solution at slightly heating with continuous stirring, on ultrasonic bath. After about 15 minutes of stirring at $40{ }^{\circ} \mathrm{C}$ the precipitate was separated from the solution, extensive washed with distilled water to remove traces of unreacted metal salt. The precipitate obtained above, washed and dried, was suspended in distilled water under continuous magnetic stirring. Over the suspension, an excess of an alcoholic solution of 1,10-phenanthroline was added until complete dissolution of the precipitate and the clear solution was kept at room temperature for slow evaporation. Crystals of coordinative compound separated after 1 month. Anal. Calcd. mass fractions of elements, $w / \%$ for $\left[\mathrm{C}_{64} \mathrm{H}_{59} \mathrm{Co}_{2} \mathrm{~N}_{8} \mathrm{O}_{17.5}\right]$ are: $\mathrm{C} 57.39 ; \mathrm{H} \mathrm{4.41;} \mathrm{N} 8.37 ; \mathrm{Co} \mathrm{8.48;}$ found: C 57.40; H 4.45; N 8.32; Co 8.52.

The obtained compound was analysed to determine the structure and then test its catalytic activity. For simplicity, the homodinuclear compound $\left[\mathrm{CO}_{2}(\mathrm{TPh})(\mathrm{O}\right.$ phen $\left.)_{4}\left(\mathrm{H}_{2} \mathrm{O}\right)_{2}\right](\mathrm{TPh})$ will be denoted $\mathrm{Co}(\mathrm{TP})$.

\section{Functionalisation of Silica}

The use of chromatographic silica type $\mathrm{G} 60$ as support is advantageous because it possesses good mechanical strength, high thermal stability and reacts easy with silanes functionalisation agents. The process of generating a thiol functional group is based on the chemical reaction between the acid groups $\mathrm{Si}-\mathrm{OH}$ and methoxy groups from (3-mercaptopropyl) -trimetoxysilane, as previous reported. [33]

\section{Immobilisation of Coordinative Compound on Functionalised Silica}

As immobilization technique the impregnation method was used. Thus, a methanol solution containing coordinative compound was placed in contact with the functionalized support and heated to reflux for 2 hours. The use of methanol is justified by the low boiling temperature, so that, the component with the possible catalytic activity does not break down. The resulting solid was filtered, washed with water and methanol and extracted by Soxhlet method for $24 \mathrm{~h}$ with alcohol in order to remove the entire unbounded metal coordination compound adsorbed into the silica matrix pores.

\section{Catalytic Activity}

Catalytic activity of the samples was evaluated in the oxidation reaction of styrene using $30 \% \mathrm{H}_{2} \mathrm{O}_{2}$ as an oxidizing agent. We choose the $\mathrm{H}_{2} \mathrm{O}_{2}$ because it is environmentally friendly, has a moderate cost, safe manipulation, and the only byproduct is water. Firstly, styrene $(4 \mathrm{mmol})$, acetonitrile $(10 \mathrm{~mL})$ and catalyst $(10 \mathrm{mg})$ were mixed and equilibrated to the desired temperature ( $75 \circ \mathrm{O}$ ) in oil bath. After the addition of $\mathrm{H}_{2} \mathrm{O}_{2}(10 \mathrm{mmol})$ the reaction mixture was stirred for $12 \mathrm{~h} .{ }^{[34]}$ The products of the styrene conversion were collected at different time, identified and quantified by chromatographic method. [35]

\section{RESULTS AND DISCUSSION}

\section{Characterization of Functionalised Silica}

Infrared spectrum of the functionalised support presents characteristic bands of the tetrahedric $\left[\mathrm{SiO}_{4}\right]^{4-}$ characterized by an increased intensity than the characteristic vibration bands of the silane agent from the system.

Characteristic vibration bands of the functionalization agent have low intensity compared to those of the starting material. ${ }^{[36]}$

After the thermal degradation of the material $(600$ ${ }^{\circ} \mathrm{C}$ ), in FT-IR spectrum was observed the disappearance of a part of the organic phase indicated by the decrease and even the absence of vibrational bands characteristic of $\mathrm{C}-\mathrm{H}$ bonds, $\mathrm{C}-\mathrm{C}$ and the increasig of the characteristic band of $\mathrm{OH}$ groups at $3300 \mathrm{~cm}^{-1}$; the characteristic bands of the $\left[\mathrm{SiO}_{4}\right]^{4-}$ do not change their position or intensity. ${ }^{[37]}$

The presence of traces of organic phase after heating at $600{ }^{\circ} \mathrm{C}$ is associated with a preferential arrangement of the silane agent into the pores of the support material. 
Table 1. BET parameters for functionalised silica

\begin{tabular}{ccc}
\hline Parameter & Silica & Functionalized silica \\
\hline Specific surface, $\mathrm{m}^{2} / \mathrm{g}$ & 616 & 523 \\
Pores volume, $\mathrm{cm}^{3} / \mathrm{g}$ & 0.866 & 0.747 \\
\hline
\end{tabular}

Measurements of specific surface at $77 \mathrm{~K}$ by nitrogen adsorption into the pores of the material indicated a type IV isotherm specific to micropores. ${ }^{[38]}$ As a result of the coupling of the adsorption -desorption isotherm is obtained a hysteresis loop of $\mathrm{H} 2$ type specific for the materials that contain network of interconnected micropores of various sizes in their structure.

The main adsorption values obtained from the measurements are shown in Table 1.

By overlaying of the adsorption isotherms of functionalized silica and support there is no difference in the hysteresis loops allure.[38] This is associated with preserved internal architecture of the channel after functionalization without destroying the internal walls of the material.

\section{Characterization of Coordinative Compound}

a. Crystal Structure Description

The main crystallographic data with refinement details are summarised in Table 2, while the bond distances and angles are summarized in Supplementary Material, Tables S1 and S2. According to X-ray crystallography the crystal structure of compound consists of dinuclear complex cations $\left[\mathrm{CO}_{2}(\mathrm{TPh})(o \text {-phen })_{4}\left(\mathrm{H}_{2} \mathrm{O}\right)_{2}\right]^{2+}, \mathrm{TPh}^{2-}$ anions and lattice water molecules in 1:1:7.5 ratio.

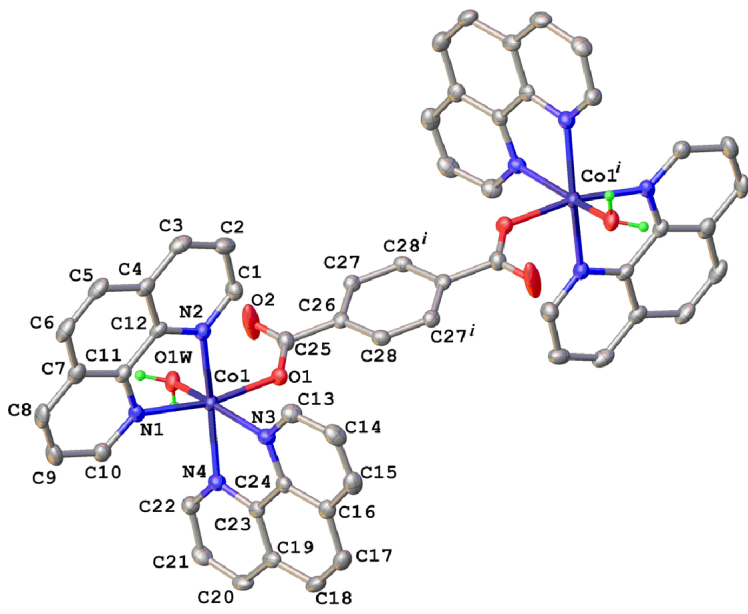

Figure 2. X-ray structure of the dinuclear cation $\left[\mathrm{CO}_{2}(\mathrm{TPh})(\mathrm{O}-\right.$ phen $\left.)_{4}\left(\mathrm{H}_{2} \mathrm{O}\right)_{2}\right]^{2+}$ with atom numbering schemes and $50 \%$ thermal ellipsoid probability for all non-hydrogen atoms.

Symmetry code: i) $-x, 2-y, 1-z$.
Table 2. Crystal data and details of crystal structure refinement

\begin{tabular}{|c|c|}
\hline Empirical formula & $\mathrm{C}_{64} \mathrm{H}_{59} \mathrm{CO}_{2} \mathrm{~N}_{8} \mathrm{O}_{17.5}$ \\
\hline Formula weight & 1338.05 \\
\hline Temperature/K & 237 \\
\hline Crystal system & triclinic \\
\hline Space group & $P / 1$ \\
\hline$a / \AA$ & $8.125(5)$ \\
\hline$b / \AA ̊ ̊$ & $12.435(5)$ \\
\hline$c / \AA$ & $15.205(5)$ \\
\hline$\alpha /^{\circ}$ & $93.702(5)$ \\
\hline$B /{ }^{\circ}$ & $92.476(5)$ \\
\hline$\gamma /{ }^{\circ}$ & $103.587(5)$ \\
\hline$V / \AA^{3}$ & $1487.4(12)$ \\
\hline$Z$ & 1 \\
\hline$D_{\text {calc }} / \mathrm{mg} / \mathrm{mm}^{3}$ & 1.494 \\
\hline$\mu / \mathrm{mm}^{-1}$ & 0.640 \\
\hline Crystal size $/ \mathrm{mm}^{3}$ & $0.10 \times 0.05 \times 0.05$ \\
\hline$\vartheta_{\min }, \vartheta_{\max }\left({ }^{\circ}\right)$ & 5.16 to 50.06 \\
\hline Reflections collected & 10155 \\
\hline Independent reflections & $5212\left[R_{\text {int }}=0.0770\right]$ \\
\hline Data/restraints/parameters & $5212 / 1 / 424$ \\
\hline$R_{1}^{(\mathrm{a})}(I>2 \sigma(I)$ & 0.0494 \\
\hline$w R_{2}{ }^{(b)}$ (all data) & 0.1115 \\
\hline $\mathrm{GOF}^{c}$ & 1.011 \\
\hline Largest diff. peak/hole/e $\AA^{-3}$ & $0.45 /-0.60$ \\
\hline
\end{tabular}

(a) ${ }^{a} R_{1}=\Sigma|| F_{\mathrm{o}}|-| F_{\mathrm{c}}|| / \Sigma\left|F_{\mathrm{o}}\right|$.

(b) $W R_{2}=\left\{\Sigma\left[w\left(F_{\mathrm{o}}^{2}-F_{\mathrm{c}}^{2}\right)^{2}\right] / \Sigma\left[w\left(F_{\mathrm{o}}^{2}\right)^{2}\right]\right\}^{1 / 2}$.

$\mathrm{GOF}=\left\{\Sigma\left[w\left(F_{\mathrm{o}}^{2}-F_{\mathrm{c}}^{2}\right)^{2}\right] /(n-p)\right\}^{1 / 2}$, where $n$ is the number of reflections and $p$ is the total number of parameters refined.

The X-ray structure of the dinuclear cluster is depicted in Figure 2. The own Ci symmetry of the dinuclear entities is induced by the crystallographic inversion center, which is located at the middle of the benzene ring of the bridging terephthalate ligand. Both symmetry equivalent Co atoms display a slightly distorted $\mathrm{N}_{4} \mathrm{O}_{2}$ octahedral coordination, provided by two bidentate $o$-phenathroline neutral molecules, and two oxygen atoms from water molecule and carboxylate group, coordinated as monodentate ligands. The second oxygen atom of carboxylate groups are involves as acceptor in the hydrogen bond towards coordinate water molecule as acceptor. The whole structure as well as the geometric parameters for $\left[\mathrm{CO}_{2}(\mathrm{TPh})(o \text {-phen })_{4}\left(\mathrm{H}_{2} \mathrm{O}\right)_{2}\right]^{2+}$ complex cation are very close to that found by Yun Niu et al. ${ }^{[39]}$ The second terephthalate double-deprotonated anion, which plays the role of the anion are not involved into the coordination to Co atom.

In the crystal, all the ionic as well as the neutral entities are interacting through $\pi-\pi$ stacking interactions and $\mathrm{O}-\mathrm{H} \cdots \mathrm{O}$ hydrogen bonding to form a strong consolidated three-dimensional supramolecular architecture. It results from the interpenetration of two selfsufficient 2D sub-lattices, as shown in Figure 3 . The first lattice (Figure 3a) is built up from the dinuclear complexes associated via $\pi-\pi$ stacking, which is realized between 


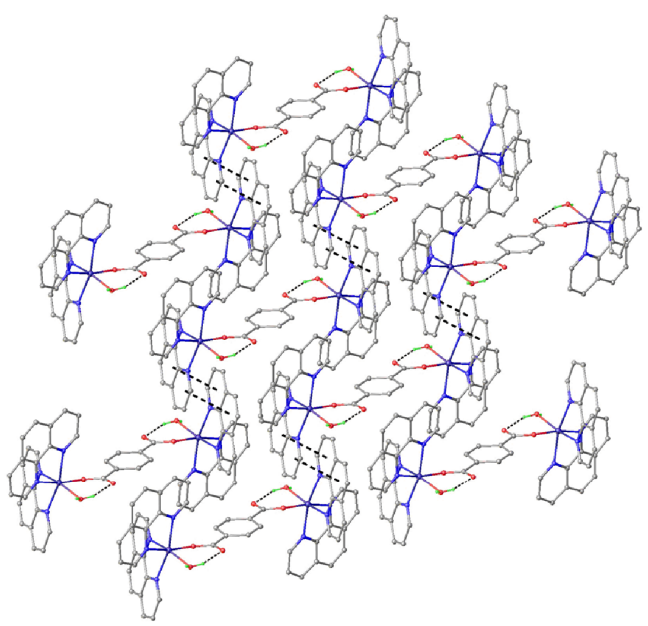

(a)

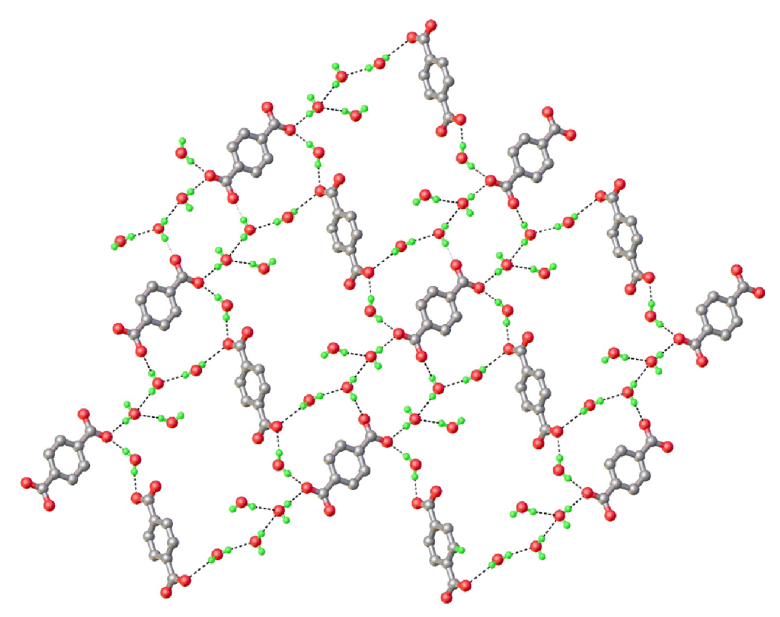

(b)

Figure 3. 2D supramolecular network fomed by stacking interacting dinuclear complexes (a); 2D supramolecular network formed by $\mathrm{H}$-bonded outer sphere units. (b).

aromatic systems of the $o$-phenanthroline ligands, with the centroid-to-centroid distance of 3.656(5) A. The second
Table 4. The main wavenumber of the vibration characteristic of $\mathrm{Co}(\mathrm{TP})$ compound and disodium terephthalate salt

\begin{tabular}{cccccc}
\hline Vibration & $\begin{array}{c}\mathrm{C}=\mathrm{O} \\
\text { (asymmetrically) }\end{array}$ & $\begin{array}{c}\mathrm{C}=\mathrm{O} \\
\text { (symmetrically) }\end{array}$ & $\mathrm{C}-\mathrm{N}$ & $\mathrm{C}-\mathrm{H}$ & $\mathrm{O}-\mathrm{H}$ \\
\hline $\begin{array}{c}\text { Terephthalic } \\
\text { Salt }\end{array}$ & 1555 & 1385 & - & 3058 & - \\
Co(TP) & 1623 & 1361 & & & \\
& 1563 & 1421 & 1515 & 3060 & 3244 \\
\hline
\end{tabular}

one (Figure $3 \mathrm{~b}$ ) comprises the $\mathrm{TPh}^{2-}$ anions and solvate water molecules being sustained through numerous $\mathrm{O}-\mathrm{H} \cdots \mathrm{O}$ hydrogen bonding. The relevant characteristics of the $\mathrm{H}$-bonds are depicted in Table 3. The linkage between two sub-lattice is provided by $\pi$ - $\pi$ stacking interactions involving outer sphere TP2- anions and o-phenanthroline ligands (centroid-to-centroid distance of 3.760(5) $\AA$ ) and by hydrogen bonds between solvate water molecules as donor towards non-coordinated oxygen atoms of the bridging phthalate ligands.

\section{b. FT-IR Spectroscopy}

In the analysis of the IR spectrum of the synthesized coordinative compound have been found shifting of the characteristic vibration of the $\mathrm{C}=\mathrm{O}$ from carboxyl group and the appearance of the vibration corresponding to the peak of the $\mathrm{C}=\mathrm{N}$ in the structure of 1,10-phenanthroline. The main vibration bands with attribution are presented in Table 4 and Figures S1 and S2 (Supplementary material).

By comparing the IR spectrum of the disodium salt of terephthalic acid and of the obtained coordinative compound can be seen a shifting of the characteristic vibrations to higher wavenumber. A particularity observed after single-crystal structure determination using X-ray diffraction method was the presence in the unit cell of a terephthalate anion as counter-anion. This correlates well with the existence in the $1650-1350 \mathrm{~cm}^{-1}$ region of a two maximum that are specific to symmetrical and asymmetrical vibration of the coordinated, respectively uncoordinated carboxyl group.

Table 3. Hydrogen bonding parameters

\begin{tabular}{lccccc}
\hline $\mathrm{D}-\mathrm{H} \cdots \mathrm{A}$ & $\mathrm{D}-\mathrm{H}$ & $\begin{array}{c}\text { Distance }(\AA) \\
\mathrm{H} \cdots \mathrm{A}\end{array}$ & $\mathrm{D} \cdots \mathrm{A}$ & $\begin{array}{c}\text { Angle } \\
\mathrm{D}-\mathrm{H} \cdots \mathrm{A},\left(^{\circ}\right)\end{array}$ & Symmetry code \\
\hline $\mathrm{O} 1 w-\mathrm{H} \cdots \mathrm{O} 2$ & 0.86 & 1.81 & $2.60(2)$ & 152.8 & $x, y, z$ \\
$\mathrm{O} 2 w-\mathrm{H} \cdots \mathrm{O} 3 w$ & 0.85 & 2.17 & $2.965(4)$ & 156.8 & $x, y, z$ \\
$\mathrm{O} 2 w-\mathrm{H} \cdots \mathrm{O} 3$ & 0.85 & 1.91 & $2.722(4)$ & 160.1 & $x, y, z$ \\
$\mathrm{O} 3 w-\mathrm{H} \cdots \mathrm{O} 4$ & 0.85 & 2.21 & $2.90(1)$ & 168.6 & $1-x, 1-y, 1-z$ \\
$\mathrm{O} 4 w-\mathrm{H} \cdots \mathrm{O} 4$ & 0.85 & 2.00 & $2.817(4)$ & 161.3 & $1-x, 1-y, 1-z$ \\
$\mathrm{O} 4 w-\mathrm{H} \cdots \mathrm{O} 2 w$ & 0.85 & 2.09 & $2.939(5)$ & 175.2 & $-1+x, y, z$ \\
$\mathrm{O} 5 w-\mathrm{H} \cdots \mathrm{O} 2$ & 0.85 & 2.21 & $2.90(1)$ & 138.7 & $x, y, z$ \\
$\mathrm{O} 4 w-\mathrm{H} \cdots \mathrm{O} 3 w$ & 0.85 & 1.96 & $2.771(5)$ & 159.8 & $x,-1+y, z$ \\
\hline
\end{tabular}


Table 5. Effect of reaction time, temperature and styrene to $\mathrm{H}_{2} \mathrm{O}_{2}$ molar ratio against catalytic activity of $\mathrm{Co}$ (TP)

\begin{tabular}{ccc}
\hline Reaction time, $\mathrm{h}$ & Conversion, $\%$ & Selectivity, $\%$ \\
\hline 2 & 32.71 & 84.39 \\
4 & 46.83 & 80.61 \\
6 & 57.49 & 77.53 \\
8 & 65.92 & 70.54 \\
10 & 78.53 & 68.65 \\
12 & 89.24 & 67.94 \\
& & \\
\hline Temperature, ${ }^{\circ} \mathrm{C}$ & Conversion, $\%$ & Selectivity, $\%$ \\
\hline 40 & 24.37 & 85.24 \\
60 & 89.75 & 79.4 \\
80 & 89.54 & 66.48 \\
& & \\
\hline Styrene: $\mathrm{H}_{2} \mathrm{O}_{2}$ molar ratio & Conversion, $\%$ & 86.74 \\
$1: 1$ & 27.85 & 80.56 \\
$1: 2$ & 47.29 & 78.21 \\
$1: 3$ & 88.54 & 76.45 \\
\hline
\end{tabular}

Assignment of the specific doublet to symmetrical/asymmetrical vibration of $\mathrm{C}=\mathrm{O}$ bond to coordinated, respectively, uncoordinated fragment is based on the difference in wavenumber specific to vibration peaks found in the spectrum.

Calculation of the difference between the wavenumber of symmetrical and asymmetrical vibration provides valuable information on how coordinate the carboxyl groups from terephthalate anion structure.

The maximum vibrations at 1622.89 and $1361.3 \mathrm{~cm}^{-1}$ $\left(\Delta=261.59 \mathrm{~cm}^{-1}\right)$ are assigned to asymmetric, respective, symmetric vibration of the monodentate terephthalate fragment between the two coordinated $\mathrm{Co}(\mathrm{II})$ ions. Vibrations from 1563.07 and $1421.86 \mathrm{~cm}^{-1}(\Delta=141.21$ $\mathrm{cm}^{-1}$ ) are assigned to (COO) group of the ionic terephthalate fragment. The presence of a large vibrational band at $3244 \mathrm{~cm}^{-1}$ suggests the presence of hydrogen bonds in the structure.

\section{c. Thermal Analysis}

The thermal analysis is a useful method to determine the stability of the coordinative compounds and to identify the possible fragments released from the compound upon heating.

Decomposition of compound starts at low temperatures (Supplementary Material, Figure S3). In the temperature range of $72-132{ }^{\circ} \mathrm{C}$ is observed a mass loss attributed to the loss of crystallization water and of the two coordination water molecules. After $132{ }^{\circ} \mathrm{C}$ temperature the coordinative compound is stable upon heating to a temperature of $241^{\circ} \mathrm{C}$, after which the thermogram presents two mass losses attributable to the elimination of coordinated and uncoordinated terephthalate fragments.

DTA curve presents three major processes that occur at the decomposition of coordinative compound. One of this can be correlated with the loss of crystallization water and of two coordination water molecules. The second and third correspond to the loss of both terephthalate anion fragment, coordinated and uncoordinated.

Loss of the coordinated water molecules to a mild heating suggests a weak coordinate $\mathrm{Co}-\mathrm{O}$ bond which makes this compound to be susceptible to the heterogeneity processes on a surface with functional groups. Heterogeneity process takes place through the coordination of the functional groups to $\mathrm{Co}(\mathrm{II})$ and replacing coordinated water molecules.

\section{d. Catalytic Activity}

Oxidation of Styrene using Hydrogen Peroxide in Presence of the Catalyst

Generally, styrene oxidation gives styrene oxide, benzaldehyde, benzoic acid and other compounds in appreciable yield. Benzaldehyde represents an important organic intermediate in the production of some chemical and in the synthesis of different odorous components. From this reason we tested the catalytic potential of the synthesized compound immobilized on the functionalized silica matrix in the oxidation of the styrene. ${ }^{[40]}$ In absence of the catalyst, the styrene conversion in the presence of aqueous solutions of $\mathrm{H}_{2} \mathrm{O}_{2}$ is close to $4 \%$ after $24 \mathrm{~h}$ reaction time. ${ }^{[41]}$ The products of the conversion reaction of styrene in presence of $\mathrm{H}_{2} \mathrm{O}_{2}$ were collected at different time, identified and quantified by chromatographic method (Figure S4, Supplementary material).

\section{Effect of Temperature}

The effect of temperature on the oxidation of styrene was investigated at three different temperatures: 40,60 and 80 oC, maintaining the other parameters constant: styrene amount (4 mmol), $30 \% \mathrm{H}_{2} \mathrm{O}_{2}$ (10 mmol), catalyst amount (10 $\mathrm{mg}$ ) and reaction time ( $12 \mathrm{~h})$. The results shown in Table 5 
Table 6. Comparative results of catalytic activity of the immobilized coordinative

\begin{tabular}{|c|c|c|c|}
\hline Catalyst & Conversion (\%) & Selectivity (\%) Benzaldehyde & Reference \\
\hline VO - Salen-SBA & 84.1 & 83.3 & 40 \\
\hline Polymer supported cobalt complex & 100 & 89 & 42 \\
\hline Cu-SBA-15 & 84.4 & 83.9 & 26 \\
\hline Cu-Salen-SBA & 96.9 & 45.2 & 40 \\
\hline $\mathrm{Co}-\left[\mathrm{H}_{2}\right]$ salen-SBA & 78.5 & 43.6 & 43 \\
\hline Co(TP)-Silica-SH & 89.75 & 85.4 & This study \\
\hline Mn(bipy)-Al-MCM 41 & 52 & 8 & 44 \\
\hline VO\{Me4(Et)2[14]tetraneN4\}-MT & 65.9 & 53.9 & 45 \\
\hline$[\mathrm{Co}\{\mathrm{Me} 4(\mathrm{Et}) 2[14]$ tetraneN4\}]-Y & 83 & 39.4 & 46 \\
\hline
\end{tabular}

reveal that $24.37 \%, 89.75 \%$ and $89.54 \%$ of conversion was found corresponding to the temperature of 40,60 and 80

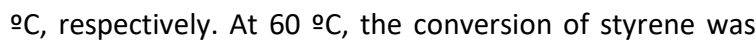
$89.75 \%$ with $79.4 \%$ selectivity of benzaldehyde. For this reason, further optimization of the conditions was carried

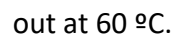

Effect of the Molar Ratio Styrene: $\mathrm{H}_{\mathbf{2}} \mathrm{O}_{\mathbf{2}}$

In order to determine the effect of $\mathrm{H}_{2} \mathrm{O}_{2}$ amount on the oxidation process of styrene we studied different molar ratios of styrene to $\mathrm{H}_{2} \mathrm{O}_{2}(1: 1,1: 2,1: 2.5$, and 1:3), keeping other parameters constant: catalyst $(10 \mathrm{mg})$, temperature $(60 \stackrel{\circ}{ })$ and reaction time $(12 \mathrm{~h})$. The obtained results are presented in Table 5. Conversion of styrene to benzaldehyde at molar ratio of 1:1 and 1:2.5 was 27.85 and $88.54 \%$, respectively. Conversion was found to remain approximately the same (88.23 \%) when the styrene: $\mathrm{H}_{2} \mathrm{O}_{2}$ molar ratio was changed to $1: 3$.

\section{Effect of Reaction Time}

The effect of the reaction time on the oxidation of styrene was studied by performing the reaction of styrene ( $1 \mathrm{mmol}$ ) with $30 \% \mathrm{H}_{2} \mathrm{O}_{2}(2.5 \mathrm{mmol})$ in presence of $10 \mathrm{mg}$ of catalyst at $60 \stackrel{\circ}{ } \mathrm{C}$ with constant stirring. The conversion percentage was calculated at different reaction times. The obtained results (Table 5) show that the percentage of conversion increases with the increasing of the reaction time with a maximum value at 12 hours.

As a consequence, the optimum conditions for a maximum \% conversion of styrene to benzaldehyde are characterized by the molar ratio of styrene to $\mathrm{H}_{2} \mathrm{O}_{2}$ of $1: 2.5$,

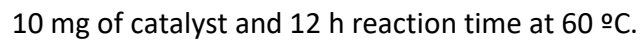

In these conditions, we found that this heterogeneous catalyst gave viable results compared with the other results from the literature from point of view of conversion and selectivity (Table 6).

On the basis of our experimental results and those reported in the literature, ${ }^{[46,47]}$ we supposed that $\mathrm{Co}$ (II) could bond the peroxo group in presence of $\mathrm{H}_{2} \mathrm{O}_{2}$, and hydroperoxo intermediate species transfer oxygen atoms to the organic substrate to give the final products. $X$-ray analysis of the coordinative compound reveals that the coordination environment of $\mathrm{Co}(\mathrm{II})$ ion allows the replacement of any coordination site to form the peroxo intermediate.

\section{CONCLUSIONS}

We have reported the synthesis of a homodinuclear coordinative compound of $\mathrm{Co}$ (II) with o-phenanthroline and terephthalate bridge. The obtained compound was immobilized on functionalized silica and tested from point of view of catalytic properties in oxidation reaction of styrene in presence of hydrogen peroxide. The obtained results pointed that the homodinuclear coordinative compound of $\mathrm{Co}(\mathrm{II})$ with o-phenanthroline and terephthalate bridge immobilized on functionalized silica is an efficient catalyst for the oxidation of styrene in presence of $\mathrm{H}_{2} \mathrm{O}_{2}$.

Supplementary Information. CCDC-1406035 contains the supplementary crystallographic data for this contribution. These data can be obtained free of charge via www.ccdc.cam.ac.uk/conts/retrieving.html (or from the Cambridge Crystallographic Data Centre, 12 Union Road, Cambridge CB2 1EZ, UK; fax: (+44) 1223-336-033; or deposit@ccdc.ca.ac.uk.

\section{REFERENCES}

[1] C. C. Wang, Y. Q. Zhang, T. Zhu, X. Y. Zhang, P. Wang, S. J. Gao, Polyhedron, 2015, 90, 58.

[2] C. Jiao, C. He, J. Geng, G. Cui, Transition Met. Chem. 2012, 37, 17.

[3] S. Choubey, S. Roy, K. Bhar, R. Ghosh, P. Mitra, C. Lin, J. Ribas, B. Ghosh, Polyhedron, 2013, 55, 1.

[4] K. Burger, P. Chaudhuri, K. Wieghardt, B. Nuber, Chem. Eur. J. 1995, 1, 583.

[5] M. R. Maurya, M. Bisht, F. Avecilla, Ind. J. Chem. 2011, 50A, 1562.

[6] S. Shit, U. Yadava, D. Saha, R. Frohlich, J. Coord. Chem., 2013, 66(1), 66. 
[7] S. Bal, S. S. Bal, Adv. Chem. 2014, Article ID 506851 http://dx.doi.org/10.1155/2014/506851.

[8] S. M. Islam, A. S. Roy, P. Mondal, M. Mubarak, S. Mondal, D. Hossain, S. Banerjee, S. C. Santra, J. Mol. Catal. A: Chem. 2011, 336, 106.

[9] S. Ribeiro, L. Cunha-Silva, S. S. Balula, S. Gago, New J. Chem. 2014, 38, 2500.

[10] D. Xureb, J. Dzierzak, R. Raja, Catal. Today, 2012, 198, 19.

[11] C. E. Song, E. J. Roh, B. M. Yu, D. Y. Chi, S. C. Kim, K. J. Lee, Chem. Commun. 2000, 7, 615.

[12] L. Canali, E. Cowan, H. D. Deleuze, C. L. Gibson, D. C. Sherrington, J. Chem. Soc. Perkin Trans. 2000, 1, 2055.

[13] Y. Yang, Y. Zhang, S. J. Hao, J. Q. Guan, H. Ding, F. P. Shang, P. P. Qiu, Q. B. Kan, Appl. Catal. A: Gen. 2010, 381, 274.

[14] G.-J. Kim, J.-H. Shin, Tetrahedron Lett. 1999, 40, 6827.

[15] Y. Yang, H. Ding, S. J. Hao, Y. Zhang, Q. B. Kan, Adv. Organomet. Chem. 2011, 25, 262.

[16] I. L. Viana Rosa, C. M. C. P. Manso, O. A. Serra, Y. lamamoto, J. Mol. Catal. A: Chem. 2000, 160, 199.

[17] R. I. Kureshy, N. H. Khan, S. H. R. Abdi, I. Ahmad, S. Singh, R. V. Jasra, J. Catal. 2004, 221, 234.

[18] M.-C. Hsiao, S.-T. Liu, Catal. Lett. 2010, 139, 61.

[19] D. R. Burri, K.-W. Jun, Y.-H. Kim, J. M. Kim, S.-E. Park, J.S. Yoo, Chem. Lett. 2002, 212, 212.

[20] D. R. Burri, R. S. Isak, K.-M. Choi, S.-E. Park, Catal. Comm. 2007, 8, 731.

[21] I. Timokhin, Synthesis and characterization of new metal-organic frameworks with nitrogen ligands. PhD thesis, Camerino University, 2012.

[22] D. S. Shephard, W. Zhou, T. Maschmeyer, J. M. Matters, C. L. Roper, S. Parsons, B. F. G. Johnson, M. J. Duer, Angew. Chem. Int. Ed. 1998, 37, 2719.

[23] A. R. Silva, V. Budarin, J. H. Clark, C. Freire, B. Castro, Carbon 2007, 45, 1951.

[24] P. Oliveira, A. Machado, A. M. Ramos, I. Fonseca, F. M. Braz Fernandes, A. M. Botelho do Rego, J. Vital, Microp. Mesop. Mat. 2009, 120, 432.

[25] Z. Zhang, Y. Zhi-Wu, Z. Min, F. Chun Yan, Synth. React. Inorg. Met.-Org. Chem. 2008, 38, 352.

[26] Z. Xuecheng, S. Ruwei, L. Zhang, Chin. J. Catal. 2014, $35,1716$.
[27] D. Sadhukhan, M. Maiti, E. Zangrando, S. Pathan, S. Mitra, A. Patel, Polyhedron 2014, 69, 1.

[28] S. Brunauer, P.H. Emmet, E. Teller, J. Am. Chem. Soc., 1938, 60, 309.

[29] E. P. Barret, L. G. Joyner, P. P. Halenda, J. Am. Chem. Soc. 1951, 73, 373.

[30] CrysAlis RED, Oxford Diffraction Ltd.,Version 1.171.34.76, 2003.

[31] O. V. Dolomanov, L. J. Bourhis, R. J. Gildea, J. A. K. Howard, H. Puschmann, J. Appl. Cryst. 2009, 42, 339.

[32] G. M. Sheldrick, Acta Cryst. 2008, A64, 112.

[33] C. Blegescu, D. Ganju, M. N. Palamaru, Rev. Roum. Chim. 2012, 57(7-8), 769.

[34] L. Lubis, S. Yuliati, L. Ling, I. Sunpono, H. Nur, Chem. Eng. J. 2012, 209, 486.

[35] L. Ahmad, B. Koohestani, S. Bhatia, S. B. Ooi, Int. J. Appl. Ceram. Technol. 2012, 9, 588.

[36] L. Saikia, D. Srinivas, P. Ratnasamy, Microp. Mesop. Mat. 2007, 104, 225.

[37] C. Blegescu, Polinuclear compounds immobilized onto inorganic supports used in catalysis, PhD Thesis, lasi, 2013.

[38] S. Rao, K. N. Munshi, N. N. Rao, J. Molec. Catal. A: Chem. 2000, 156, 205.

[39] S. Yun Niu, J. Jin, Z. Zhi Yang, Synth. React. Inorg. Met.-Org. Chem. 2004, 34, 173.

[40] Y. Yang, Y. Zhang, S. J. Hao, J. Q. Guan, H. Ding, F. P. Shang, P. P. Qiu, Q. B. Kan, Appl. Catal. A 2010, 381, 274.

[41] Z. Wangcheng, G. Yanglong, W. Yahquin, G. Yun, L. Guanzhong, J. Rare Earths 2010, 28, 369.

[42] B. Tamami, S. Ghasemi, Appl Catal A 2011, 393, 242.

[43] Y. Yang, Y. Zhang, S.J. Hao, Q.B. Kan, Chem. Eng. J. 2011, 171, 1356.

[44] K. Seong-Su, W. Zhang, T.J. Pinnavaia, Catal. Lett. 1997, 43, 149.

[45] L. Zhifang, D. Hong, W. Shujie, L. Heng, S. Hailiang, S. Jian, Z. Dafang, H. Qisheng, G. Jingqi, K. Qiubin, Mat. Res. Bull. 2013, 48, 1920.

[46] L. Zhifang, W. Shujie, M. Yuanyuan, L. Heng, H. Jing, L. Lulu, H. Qisheng, G. Jingqi, K. Qiubin, Transition Met. Chem., 2013, 38, 243.

[47] M. Salavati-Niasari, J. Mol. Catal. A: Chem. 2009, 310, 51. 